\title{
DESAFIOS DA DOCÊNCIA BILÍNGUE NO ENSINO REGULAR PRIVADO NO BRASIL
}

\section{ARTIGO ORIGINAL}

SOUSA, Cynara Tavares de ${ }^{1}$

CAMARGO, Patrícia Gimenez ${ }^{2}$

SOUSA, Cynara Tavares de. CAMARGO, Patrícia Gimenez. Desafios da docência bilíngue no Ensino Regular Privado no Brasil. Revista Científica Multidisciplinar Núcleo do Conhecimento. Ano 05, Ed. 09, Vol. 04, pp. 163-181. Setembro de 2020. ISSN: 2448-0959, Link de acesso: https://www.nucleodoconhecimento.com.br/educacao/docencia-bilingue

\section{RESUMO}

A prática do ensino bilíngue no Brasil tem se tornado cada vez mais comum. Diante de um cenário que cresce de forma tão vertiginosa, questionamos: quais seriam os obstáculos que os profissionais dessa área enfrentam nesse contexto escolar contemporâneo? O propósito deste estudo foi o levantamento dos desafios que os professores enfrentam na prática do ensino bilíngue privado no Brasil através do emprego da metodologia Aprendizado Integrado de Língua e Conteúdo ou CLIL (Content and Language Integrated Learning), abordagem educacional estudada e debatida por diversos autores (COYLE, 2010; HOOD, 2010; MARSH, 2010). No total, 87 professores de colégios particulares bilíngues ou com programas bilíngues

\footnotetext{
1 Pós-graduação em Psicopedagogia (2015), Licenciatura em Letras - Inglês (2018), Graduação em Pedagogia (2018) e Bacharelado em Tradução e Interpretação (2009). 2 Orientadora. Doutorado em Estudos Da Tradução. Mestrado em Linguística. Especialização em Psicopedagogia Clínica E Institucional. Especialização em Gestão Escolar. Especialização em Gramática da Língua Inglesa. Graduação em Letras/ Tradutor Interprete.
} 
responderam ao questionário criado para essa análise que apresentou duas fases: a investigação sobre o próprio conhecimento da língua e a vivência na profissão no contexto atual. Cinco desafios essenciais foram identificados. Eles foram a indisciplina dos alunos; a adaptação do conteúdo ou da aula para alunos com diferentes níveis de conhecimento da língua; alunos com dificuldades de aprendizagem; problemas com a gestão da escola e a quantidade de alunos em sala de aula. Com esse resultado podemos concluir que no contexto da docência bilíngue no cenário brasileiro privado de educação regular os desafios diferem dos já estudados em nível mundial.

Palavras-chave: Ensino bilíngue, CLIL, docência bilíngue.

\section{INTRODUÇÃO}

O ensino da língua inglesa no Brasil não começou há pouco, na realidade teve início em 1809 quando D. João VI fugiu de Portugal e veio para o Brasil (LIMA, 2017). Com o avanço da globalização, o domínio de uma segunda língua tem se tornado cada mais vez mais necessário para fins sociais, culturais, tecnológicos e comerciais, a língua, língua franca para esses fins. A língua inglesa. Com a rapidez com a qual essa demanda pela aprendizagem da língua inglesa cresce, aumenta também a necessidade em dominar esse idioma cada vez mais cedo.

Essa evolução global também traz a necessidade de docentes cada vez mais preparados para atuar no contexto da educação bilíngue e, com isso, surgem também os desafios da prática que enfrenta hoje um cenário nunca antes visto: o da educação regular bilíngue, cenário este que se dá, primordialmente, através da abordagem CLIL (COYLE, 2010; HOOD, 2010; MARSH, 2010), que é uma abordagem educacional com foco tanto no conteúdo quanto na língua pelo qual esse conteúdo é ministrado.

Considerando que qualquer abordagem educacional apresenta, após certo tempo de implantação, desafios e pontos de reflexão, no caso do CLIL não seria diferente, ela começa agora, após mais de vinte anos a trazer pontos de consideração tanto relacionados à prática quanto à docência e partindo desse movimento há a reflexão 
sobre quais são os principais desafios da docência bilíngue no ensino regular privado no contexto brasileiro.

O objetivo desse artigo é conhecer e melhor entender os desafios que o docente enfrenta nesse processo bilíngue no Brasil, desafios esses que ainda são de desconhecimento na área da educação. Através das descobertas realizadas será então possível para diretores e coordenadores melhor direcionarem o processo de formação desses profissionais que, muitas vezes, não passam por capacitações na área e acabam sem o suporte necessário para desempenhar um trabalho escolar de qualidade.

O interesse pela descoberta desses desafios se deu através da própria necessidade da autora que trabalha com a formação de docentes de ensino bilíngue, a partir da intenção de melhor desenvolver os profissionais que atende, assim surgiu a necessidade de entender quais reais situações acontecem dentro da sala de aula que podem vir a afetar o trabalho do professor bilíngue.

Uma pesquisa de campo com professores que atuam no ensino bilíngue foi realizada com o objetivo de gerar o levantado desses desafios. Voluntariamente, profissionais responderam um questionário desenvolvido pela autora e disparado em grupos relacionados ao ensino bilíngue em redes sociais, esse questionário foi desenvolvimento cautelosamente a fim de oferecer o máximo de causas que podem afetar o trabalho do docente; há também perguntas específicas para mapear a região, a proficiência e a escolaridade desses voluntários. Ainda, adicionou-se um sistema de filtragem, que impossibilita a participação de quem não está dentro do campo de interesse do estudo. Depois da fase de coleta, os resultados foram minunciosamente estudados e os cinco principais desafios elencados através de porcentagem. Há, então, uma reflexão final que discute os resultados desse estudo. 


\section{UMA BREVE DISCUSSÃO SOBRE O MERCADO BILÍNGUE}

\subsection{BILINGUISMO}

O conceito do bilinguismo envolve muitas esferas, mas comecemos com a terminologia formal. O dicionário Cambridge, por exemplo, define o bilinguismo como a capacidade de usar duas línguas igualmente bem. Já o dicionário Oxford determina que se trata da fluência ou uso de duas línguas, definição esta, que se assemelha com a do dicionário Michaelis de língua portuguesa.

Nos ateremos neste estudo ao bilinguismo em seu entendimento no aspecto educacional. Em seu livro Foundations of Bilingual Education and Bilingualism, Colin Baker explica o bilinguismo analisando-o em diferentes dimensões e até chega a mencionar ser impossível definir quem, de fato, é ou não bilíngue, uma vez que leva diversos fatores em consideração, tais como: habilidade, idade, cultura, uso, equilíbrio das duas línguas, desenvolvimento, contexto e bilinguismo eletivo.

A Cambridge International Examinations (Cambridge), usa o termo "bilíngue" ou "Bilinguismo" para se referir a indivíduos ou grupos que usam rotineiramente duas ou mais línguas para comunicação em contextos variados. No entanto, existem muitas definições e entendimentos do termo "bilíngue", por exemplo, um grau de competência em duas línguas.

\subsection{EDUCAÇÃO BILÍNGUE}

Cambridge usa "educação bilíngüe" para se referir ao uso de duas ou mais línguas como meios de instrução para matérias de "conteúdo", como ciência ou história. Para Cambridge na educação bilíngue os alunos aprendem matérias não ligadas à língua, por exemplo, geografia e história através de sua primeira língua (L1) e outras matérias não linguísticas, tais como ciências e matemática através de uma segunda / linguagem adicional (L2). Alternativamente, os alunos podem estudar a mesma matéria através de duas línguas. 
De qualquer forma, o bilinguismo difere da educação bilíngue. A educação bilíngue diz respeito àquela "em que duas línguas são usadas como meio de instrução" (HORNBERGER, 1991, p. 217) ou, de acordo com Genesee (1987, p. 1), "educação bilíngue é a instrução que ocorre na escola em pelo menos duas línguas".

Um dos sensos mais comuns é acreditar que a educação bilíngue é um fenômeno recente, que surgiu com a globalização, mas podemos até pensar, grosso modo, que o Brasil passou por este movimento, mesmo que informalmente, muito antes, já que escola para índios no Brasil começa a se estruturar a partir de 1549, quando chega ao território nacional a primeira missão jesuítica enviada de Portugal por D. João III composta por missionários da Companhia de Jesus com o padre Manuel da Nóbrega como chefe. Para se fazerem entender pelos jesuítas, pelos demais índios da aldeia e pelos colonos, os índios cristãos viam-se obrigados a aprender a língua portuguesa.

Porém, o ensino da língua inglesa no Brasil foi oficializado em 22 de junho de 1809 juntamente com o francês, deixando o latim e o grego de serem as línguas lecionadas. Essa inserção se deu após decreto de D. João IV que suportou sua decisão no argumento de que eram as que tinham mais distinto lugar entre línguas vivas e que teriam mais importância ao estado e elevariam o grau de prosperidade da instrução pública.

\subsection{CLIL}

Segundo Coyle; Hood e Marsh (2010) o Aprendizado Integrado de Língua e Conteúdo ou CLIL (Content and Language Integrated Learning) é uma abordagem educacional com foco tanto no conteúdo quanto na língua pelo qual esse conteúdo é ministrado, ou seja, durante o processo de ensino e aprendizado há o foco não somente em um, mas em ambos.

De acordo com Puffer (2011) apesar de o L em CLIL significar língua, a abordagem é majoritariamente implantada em língua inglesa. Puffer (idem) também sugere que CLIL pode ser interpretada como "uma medida de enriquecimento em língua estrangeira empacotado em ensino de conteúdo". 
O crescente interesse na abordagem CLIL pode ser compreendido através da análise de práticas docentes que são mais apropriadas para os dias atuais. A globalização juntamente com questões econômicas e sociais tiveram um impacto significativo na reflexão de quem aprende uma língua, em qual momento de seu desenvolvimento ela é desenvolvida e de que maneira esse aprendizado.

\subsubsection{O ESTUDO}

Toda abordagem educacional apresenta, após certo tempo de implantação, desafios e pontos de reflexão, no caso do CLIL não seria diferente, oficialmente nomeada com esse acrônimo em 1994 (POKRIVČÁKOVÁ, 2015), a abordagem começa agora, pouco mais de vinte anos depois, a trazer pontos de consideração tanto relacionados à prática quanto à docência.

Segundo Banegas, em seu estudo CLIL teacher development: Challenges and experiences (2012) os desafios do CLIL se iniciam com os administradores das escolas ao escolher a abordagem, porém não entendem suas próprias necessidades perante aos programas bilíngues e acabam por passar essas incertezas e falta de conhecimento para os professores que são os responsáveis pelas aulas. Questões mais relacionadas ao professor, enquanto profissional, também foram levantadas através de questionários estruturados em estudo realizado por Pena Díaz e Porto Requejo (2008), esse estudo foi realizado após o acompanhamento da implantação de programas bilíngues em 150 escolas de educação básica em Madrid e comprovou que a falta de conhecimento da língua inglesa afetava diretamente o sucesso da implantação da abordagem CLIL.

Além da falta de conhecimento da língua, professores também relataram que apesar de não terem tido treinamento formal sobre metodologias educacionais bilíngues, não consideram a necessidade de formação teórica, e sim de conhecimento prático.

Já no webinar "CLIL won't kill" ministrado por Gary Anderson e transmitido pela Cambridge English Teacher em 2014, o qual elenca os cinco principais desafios do CLIL ao redor do mundo, apresenta como as dificuldades: o nível de inglês do 
professor, que às vezes é inferior ao dos alunos, a ausência de técnicas de ensino, a forma de avaliação e a dúvida sobre como avaliar o aluno, se por via conteúdo ou língua e a frequência. Outra questão levantada é a do material didático, há muitos materiais desenvolvidos para o ensino de matérias em inglês, porém nem sempre correspondem com a base nacional curricular do país em questão, sendo essa falta de correspondência o último desafio levantado.

Ainda no foco do profissional, uma série de entrevistas que investigava quais fatores auxiliavam o professor a ter sucesso em programas CLIL, revelou que os fatores principais incluíam: oportunidades de capacitação, suporte de centros de imersão e materiais sobre docência, nesta ordem (MEHISTO'S, 2008). O mesmo estudo complementa que o endereçamento desses fatores é crucial para garantia a qualidade da abordagem (COYLE, 2007), porém, ao serem entrevistados, os coordenadores e gestores de escolas admitiram que esses fatores nunca foram, de fato, dirigidos.

\subsubsection{A INVESTIGAÇÃO}

A coleta de dados foi feita através de um questionário especialmente estruturado respondido via online por 106 voluntários da área de educação bilíngue que atualmente lecionam no mercado de educação regular no país.

O questionário foi idealizado baseando-se na análise de artigos sobre bilinguismo e desafios da prática docente e na experiência profissional da autora desta pesquisa e foi estruturado em duas partes: a primeira parte "Sobre o professor" visa fazer a triagem dos voluntários a fim de realmente filtrar quem trabalha com educação privada e bilíngue atualmente e a segunda parte "Sobre a prática do ensino" tem como objetivo focar em aspectos de região, formação e rotina desse professor, bem como os desafios que ele enfrenta em sua prática.

A fim de melhor filtrar as informações, limitou-se a escolha a cinco desafios que os voluntários apontaram utilizando-se da própria experiência. A análise dos dados foi feita através da apreciação e com a ajuda da ferramenta Google Forms que filtra dados e os apresenta de forma individual ou geral via quantidade e porcentagem. 


\section{RESULTADOS}

Apresentaremos e discutiremos os resultados da pesquisa feita com 106 voluntários. A apresentação seguirá a ordem das perguntas e o gráfico exibirá via cores, em quantidade e porcentagem as respostas coletadas.

Gráfico 1: Você leciona a língua inglesa ou via língua inglesa atualmente?

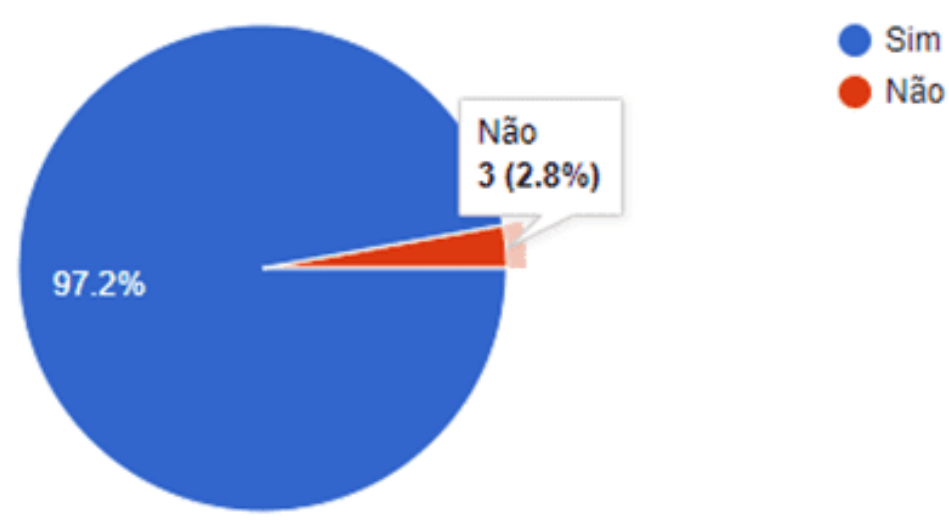

Fonte: Autoria própria (2018)

Considerando que o estudo almeja a análise dos desafios do bilinguismo no contexto atual, a primeira questão visa filtrar os voluntários que lecionam via inglesa na presente data (2018) no país. Caso o profissional não o faça, ele é automaticamente direcionado para a página de agradecimento pela colaboração e não tem acesso ao restante do questionário. Neste caso, podemos observar que 106 profissionais se dispuseram a responder às questões e colaborar com a pesquisa, sendo 103 o número real de pessoas que lecionam via língua inglesa. 
Gráfico 2: Onde você leciona atualmente?

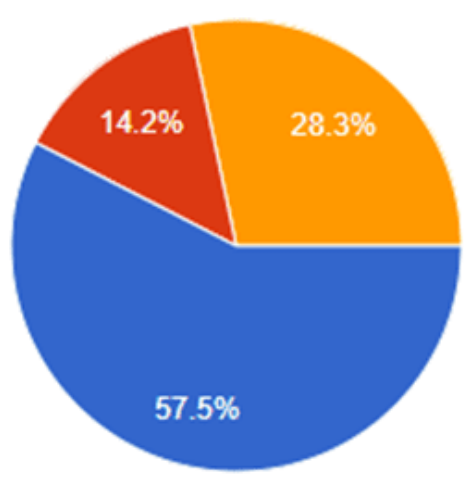

Ensino regular

Centros de idiomas/Aulas particulares

Ensino regular, centros de idiomas e aulas particulares

Fonte: Autoria própria (2018)

A segunda questão visa observar em qual segmento de ensino estes profissionais se encontram no momento e filtrar aqueles que não lecionam na área de estudo que é o ensino regular básico. Caso o profissional não o faça, ele é automaticamente direcionado para a página de agradecimento pela colaboração e não tem acesso ao restante do questionário.

Ao observar o gráfico, podemos perceber que $85,8 \%$ dos voluntários estão na área almejada para este estudo. 
Gráfico 3: Sobre o professor - Em qual região do país você leciona?

\section{Sobre o professor.}

\section{Em qual região do país você leciona?}

\section{1 responses}

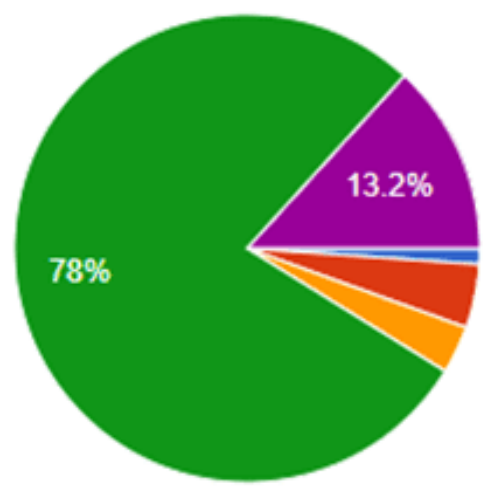

Norte

Nordeste

Centro-Oeste

Sudeste

Sul

Fonte: Autoria própria (2018)

Ao concluir a filtragem dos voluntários que lecionam no ensino básico, iniciamos a seção focada no profissional. Podemos observar no gráfico acima que dos 103 voluntários iniciais, 91 lecionam dentro da educação regular brasileira no momento sendo, em sua maioria, profissionais que atuam na região sudeste do país.

Gráfico 4: Você trabalha na rede pública ou privada de ensino básico?
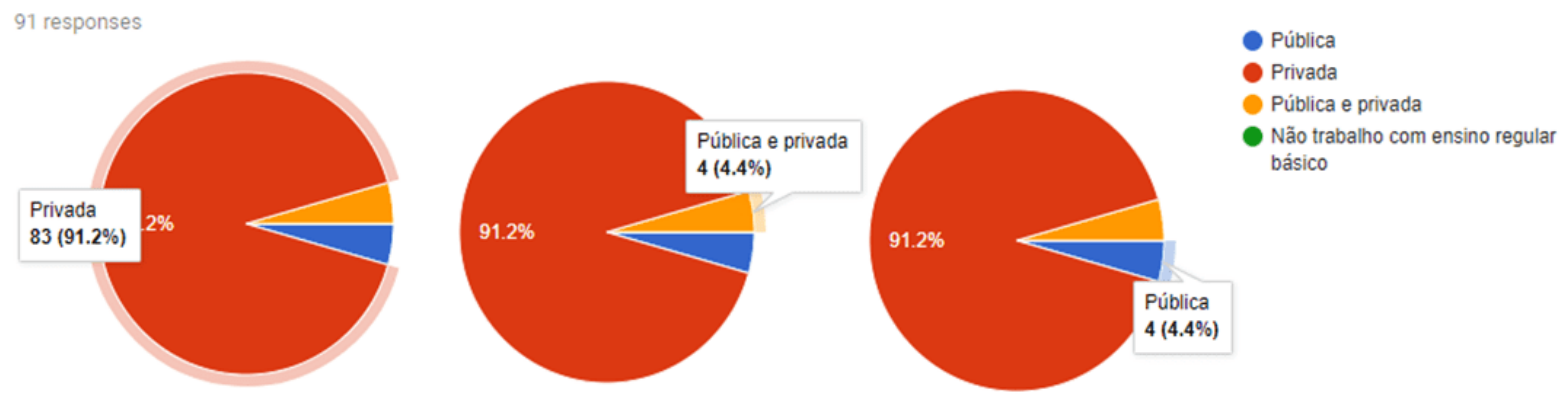

Fonte: Autoria própria (2018)

Feita a distinção de quem leciona no ensino básico brasileiro, passamos para o momento da triagem que visa focar nos profissionais do ensino básico bilíngue. Neste 
momento podemos observar que dos iniciais 106 voluntários, 91 chegaram à esta fase e sua maioria está inserida na educação regular bilíngue privada.

Gráfico 5: Qual é a sua formação acadêmica superior?

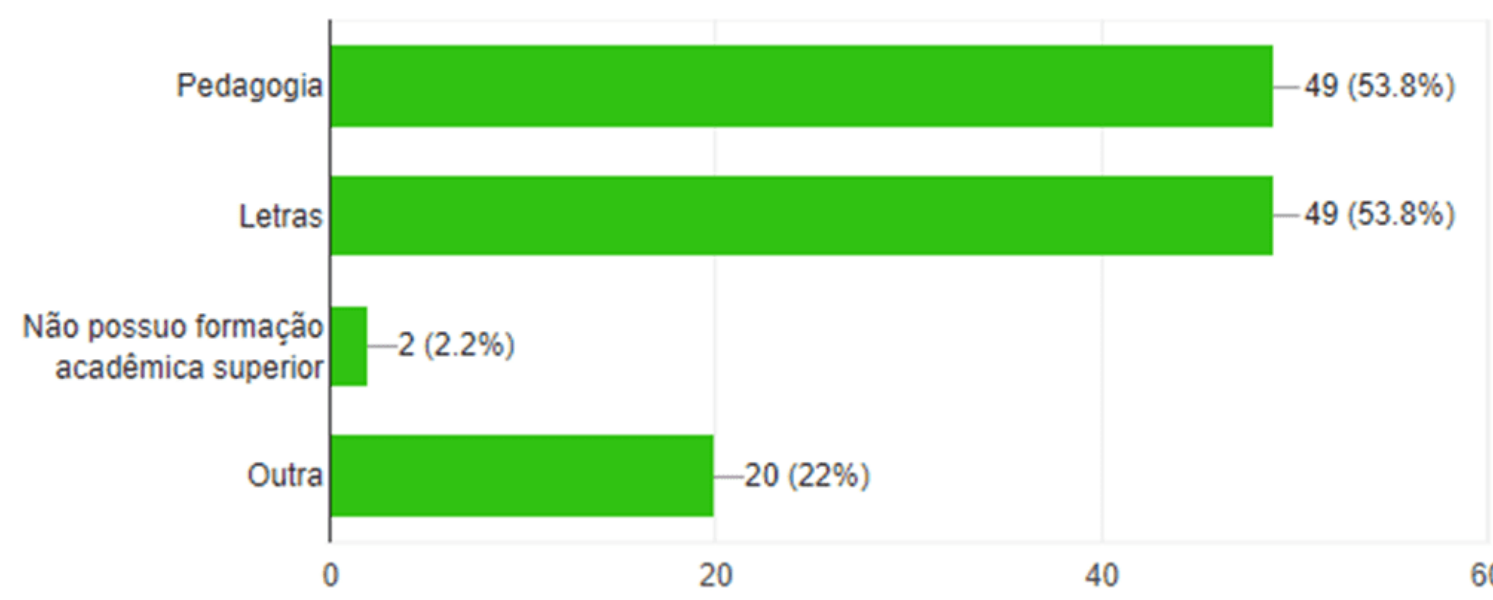

Fonte: Autoria própria (2018)

Sobre a formação acadêmica superior, podemos observar que a maior parte dos entrevistados é graduada nas áreas de Pedagogia e Letras, seguida por profissionais graduados em outras áreas.

Gráfico 6: Para quais faixas de ensino você leciona?

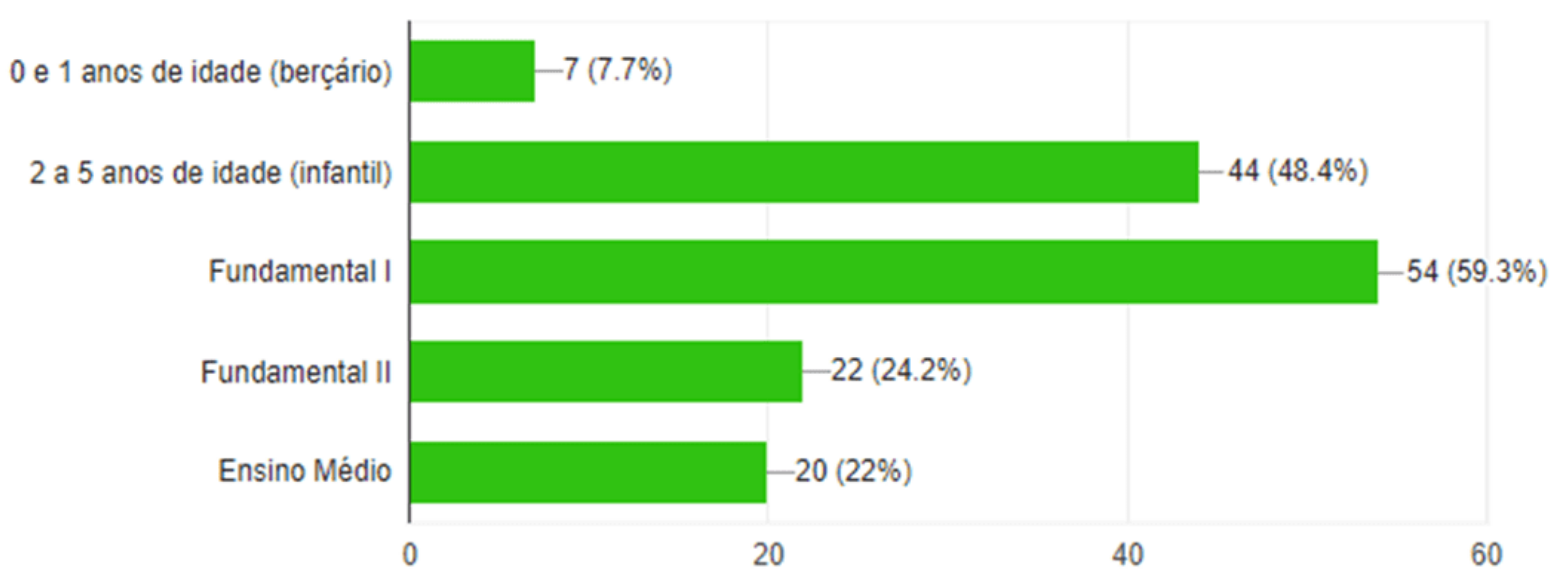

Fonte: Autoria própria (2018) 
É possível também observar que a maior parte dos profissionais lecionam nos ensinos infantil e fundamental 1.

Gráfico 7: Como você aprendeu a língua inglesa?

91 responses

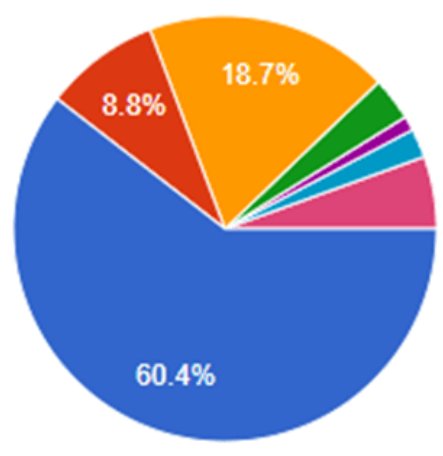

Estudo formal em centros de idiomas

De forma autodidata

Morei no exterior

Tenho familiares ou amigos nativos

Estudei em colégio bilíngue

Sou estrangeiro

Outra forma não listada

Fonte: Autoria própria (2018)

Quando questionados a respeito do próprio aprendizado da língua inglesa, podemos perceber que mais que a metade dos entrevistados aprendeu o idioma formalmente em centros de ensino de língua.

Gráfico 8: Há quanto tempo você leciona inglês ou via língua inglesa?

\section{1 responses}

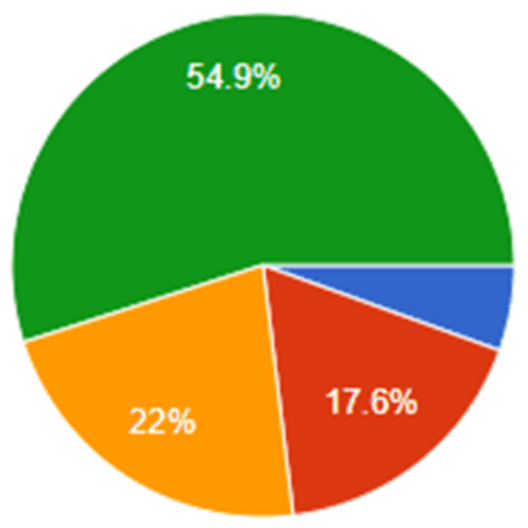

1 ano ou menos

de 2 a 5 anos

de 6 a 10 anos

mais de 10 anos

Fonte: Autoria própria (2018) 
A respeito do tempo de experiência dos entrevistados, podemos observar que 54,9\% lecionam língua ou via a língua inglesa há mais de dez anos.

Gráfico 9: Qual é o seu nível de proficiência em língua inglesa?

\section{1 responses}

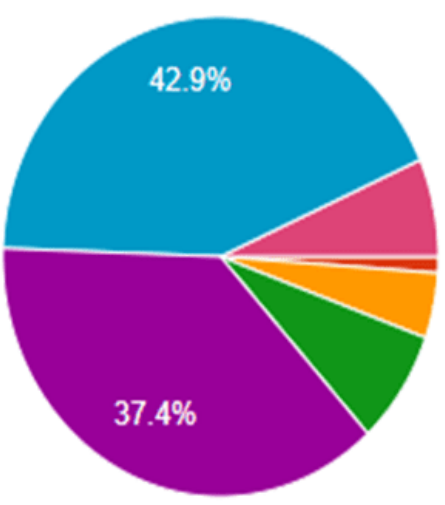

A1 - iniciante

A2 - básico

B1 - intermediário

B2 - usuário independente

C1- proficiência operativa eficaz

C2 - domínio pleno

Não sei dizer

Fonte: Autoria própria (2018)

Quando questionados a respeito da proficiência em língua inglesa pode ser observado que $80,3 \%$ possuem nível alto de proficiência.

Gráfico 10: Você possui algum certificado de ensino de língua inglesa?

\section{1 responses}

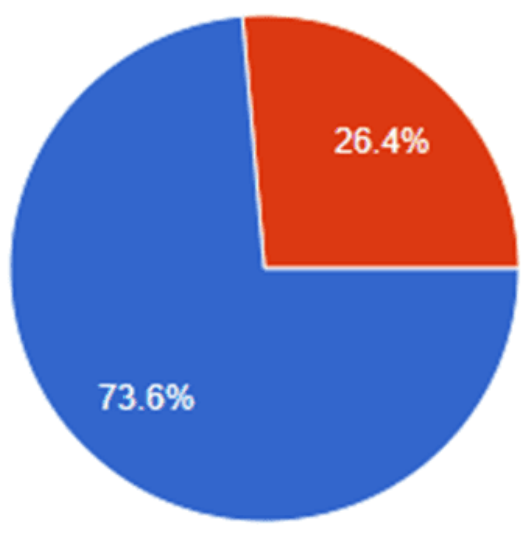

Fonte: Autoria própria (2018) 
Sobre certificações na área de docência na língua, um quarto dos entrevistados diz não possuir.

Gráfico 11: Para quantas turmas você leciona atualmente?

\section{7 responses}

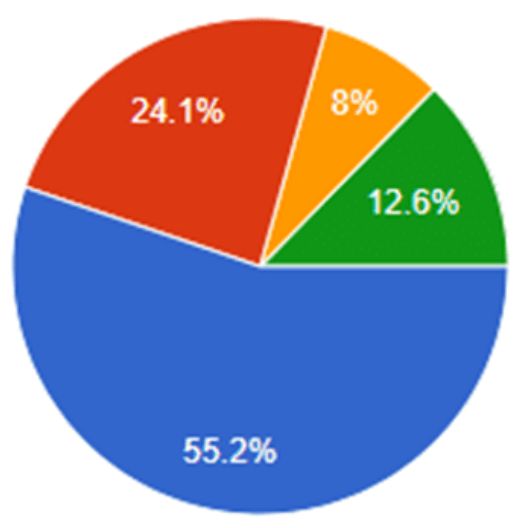

Entre 1 a 3 turmas

Entre 4 a 8 turmas

Entre 9 a 11 turmas

Mais de 12 turmas

Fonte: Autoria própria (2018)

É chegada a hora de entrevistar os voluntários a respeito de sua própria prática docente, neste momento atingimos o número real e orgânico de profissionais inseridos na área almejada para este estudo que é o ensino regular básico privado brasileiro. Dos iniciais 106 voluntários, 87 encontram-se no campo de observação deste estudo e mais que a metade desses profissionais leciona entre uma e três turmas em sua prática diária. 
Gráfico 12: Qual é a quantidade média de alunos por turma que você leciona no ensino regular básico?

\section{7 responses}

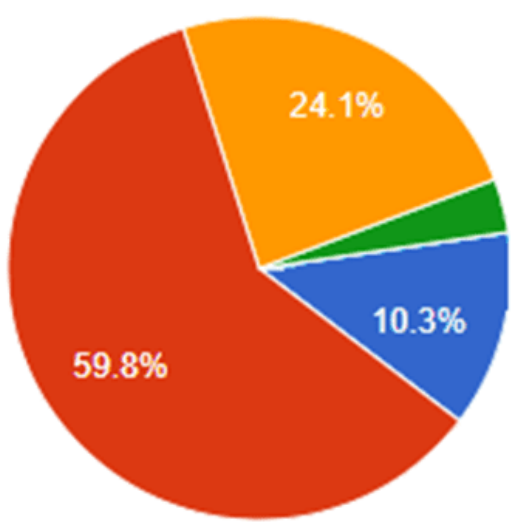

Até 10

Entre 11 e 20

Entre 21 e 30

Entre 31 e 40

Acima de 40

Fonte: Autoria própria (2018)

É possível observar que a média de alunos por turma desses profissionais está entre 11 e 20, também é possível notar que nenhum dos entrevistados possui turmas com mais de 40 alunos.

Gráfico 13: O colégio no qual você trabalha oferece formação contínua aos professores?

\section{7 responses}

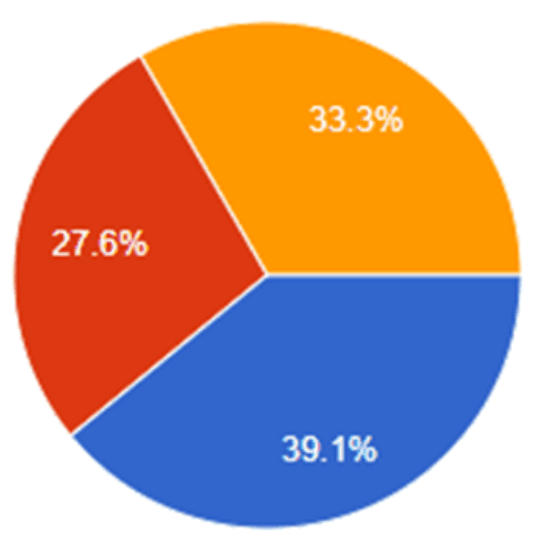

Sim

Não

Às vezes

Fonte: Autoria própria (2018) 
Quanto à capacitação de professores é possível afirmar que 24 dos 87 profissionais entrevistados trabalham em locais que não oferecem qualquer capacitação contínua aos professores.

Gráfico 14: Com qual frequência você recebe feedback sobre a sua prática docente?

\section{7 responses}

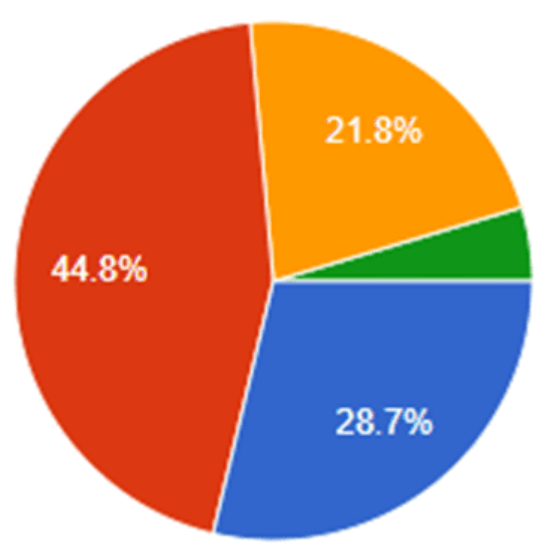

Sempre

Às vezes

Raramente

Nunca

Fonte: Autoria própria (2018)

Quando questionados sobre a frequência com a qual recebem feedback sobre a própria prática docente, $44,8 \%$ dos entrevistados admitem ocasionalmente recebêlos. 
Gráfico 15: Assinale as 5 opções que melhor refletem as suas dificuldades na sala de aula:

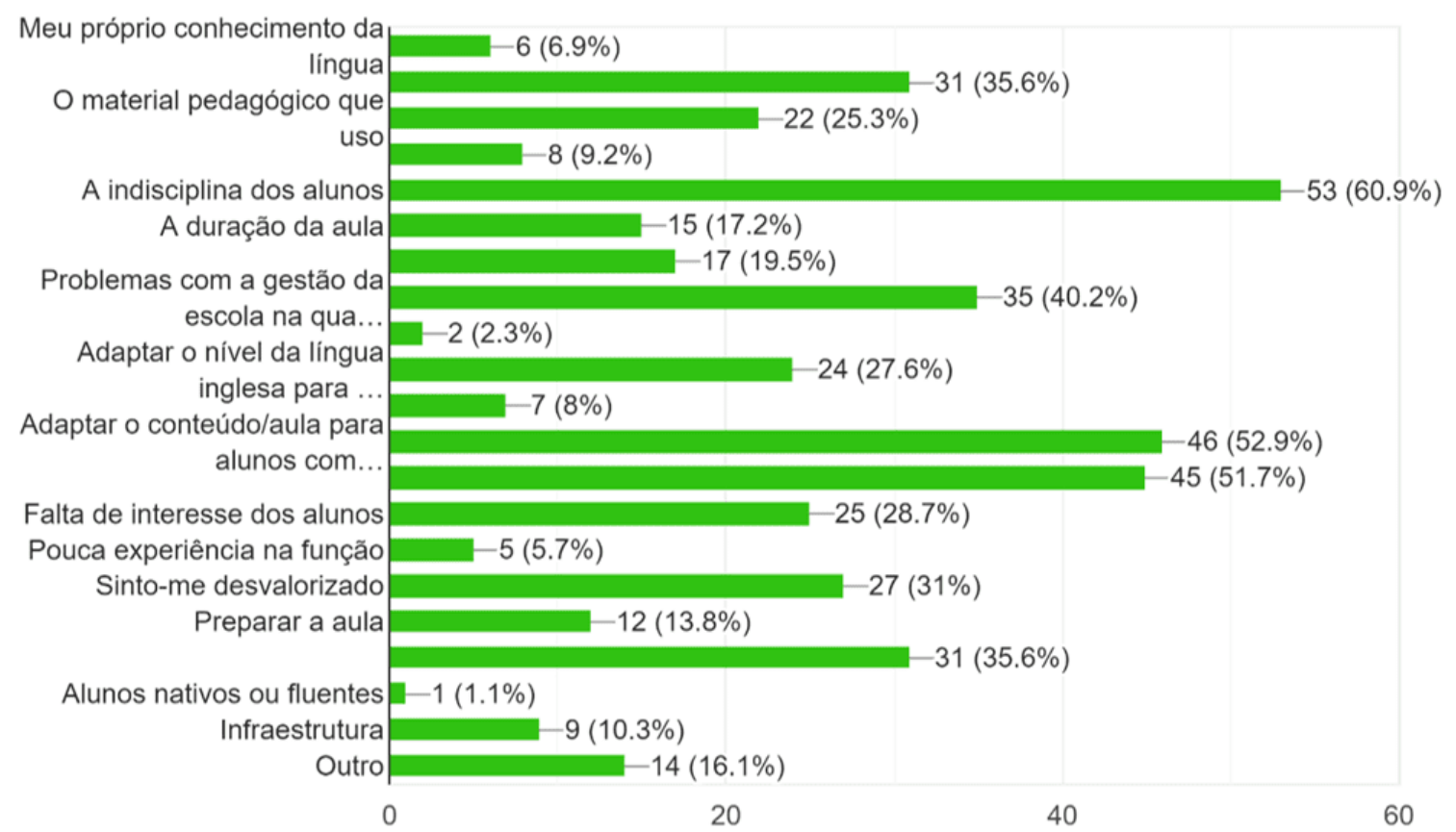

Fonte: Autoria própria (2018)

O último tópico do questionário é a respeito do tema central desta pesquisa e questiona os voluntários sobre os cinco principais desafios que enfrentam da prática de sua docência no ensino bilíngue regular e privado no Brasil. Foram apresentadas 21 opções de desafios e os voluntários os elencaram de acordo com a própria experiência, a ordem das opções variava de voluntário para voluntário. As opções e seus respectivos resultados foram:

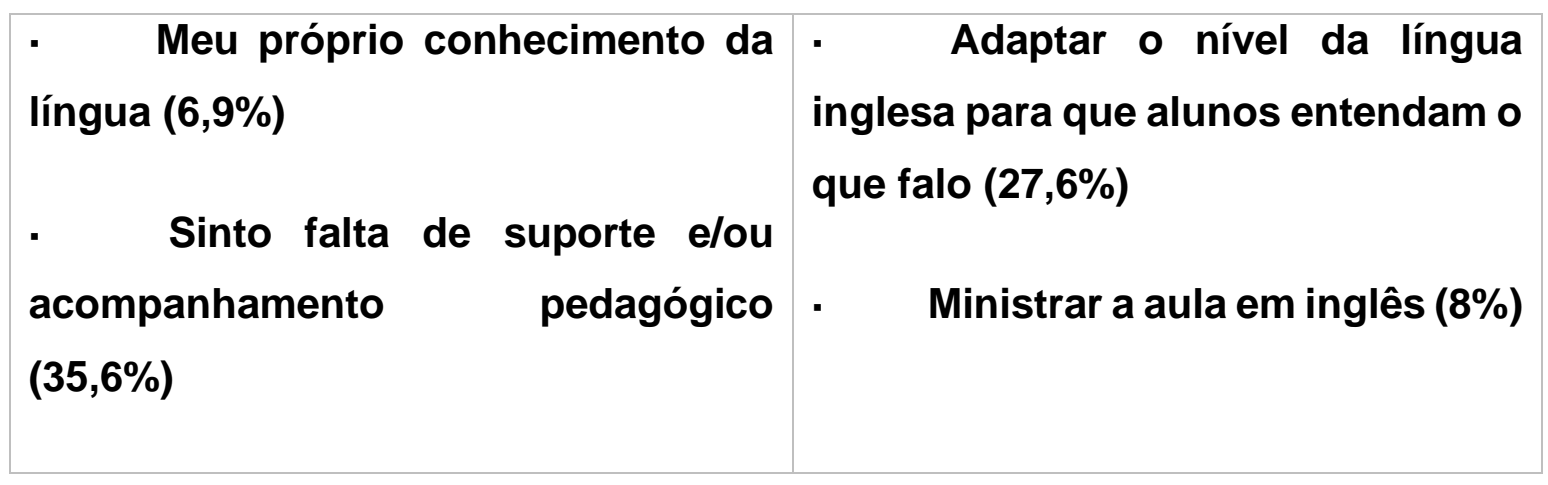




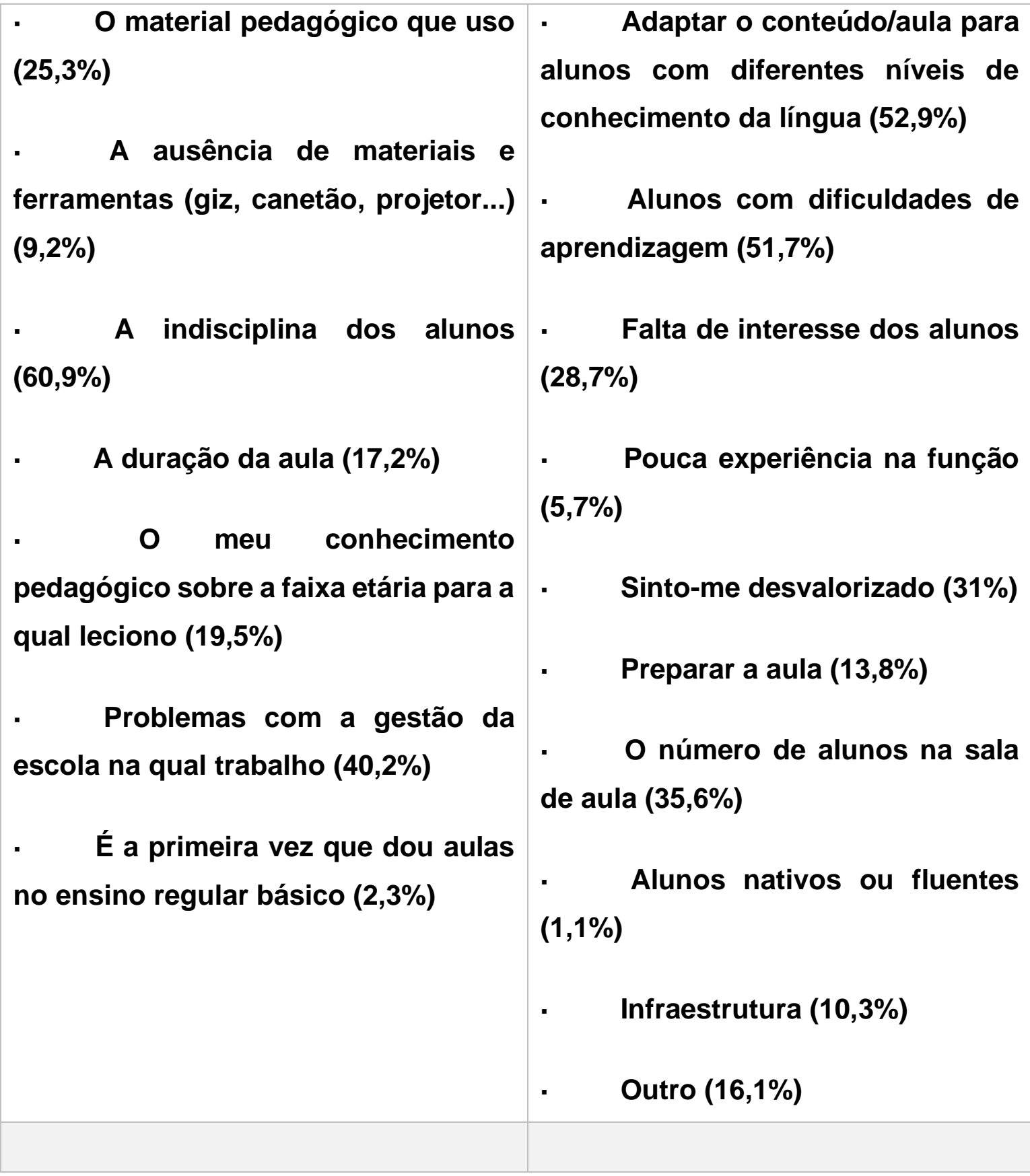

Em primeiro lugar, votado por 53 dos 87 professores, está a "Indisciplina dos alunos" seguido pela opção "Adaptar o conteúdo/aula para alunos com diferentes níveis de conhecimento da língua" com 46 votos. Em terceiro lugar está a opção "Alunos com dificuldades de aprendizagem" com 45 votos e em quarto lugar está "Problemas com a gestão da escola na qual trabalho". O último lugar no ranking ficou empatado entre dois desafios: "O número de alunos na sala de aula" e "Sinto falta de suporte e/ou acompanhamento pedagógico" ambos totalizando 31 votos cada. 
Houve também espaço para comentários extras ao final do questionário e alguns dos outros desafios mencionados incluíam questões relacionadas ao uso de língua portuguesa pelo assistente de sala, a atitude e expectativa dos pais quanto à função da escola, exigência de tratamento com exceções para regras da escola e a respeito da escola que cede às exigências dos pais.

Também foi criticada a variação de salário de professor bilíngue e o currículo em inglês de disciplinas das quais os alunos têm pouco repertório, uma vez que são preponderantes brasileiros e estão imersos na língua portuguesa, e tendo o professor a responsabilidade de fazer esse currículo acontecer em sua totalidade.

\section{DISCUSSÃO}

De acordo com os dados apresentados, avaliamos que, no contexto brasileiro o desafio número um elencado pelos profissionais da área no questionário elaborado especialmente para este estudo está relacionado à indisciplina dos alunos em sala de aula.

Tanto no estudo de Pena Díaz e Porto Requejo (2008) e no webinar "CLIL won't kill” ministrado por Gary Anderson (2014), o nível de proficiência da língua inglesa mostrou-se um desafio, porém no questionário deste estudo essa questão não foi elencada como alguns dos principais desafios sendo seis dos 87 participantes orgânicos desta pesquisa que mencionaram esse ponto.

Não houve nenhum dos tópicos que não tenha sido elencado por algum dos participantes, todos foram escolhidos pelo menos alguma vez como, por exemplo, o desafio de possuir algum aluno nativo ou fluente.

\section{CONSIDERAÇÕES FINAIS}

O presente estudo teve como objetivo entender e elencar os principais desafios da docência bilíngue no cenário privado brasileiro. Essa pesquisa se deu em três fases principais que foram: uma breve análise sobre bilinguismo, a coleta de respostas de 
professores voluntários atuantes na área através de questionário e a análise desses dados.

De acordo com os resultados encontrados podemos concluir que, no contexto da docência bilíngue no cenário brasileiro privado de educação regular os desafios diferem dos já estudados em nível mundial. No Brasil o professor bilíngue enxerga como maior desafio a indisciplina, seguida pela dificuldade em adaptar o conteúdo ou a aula para alunos com diferentes níveis de conhecimento da língua, os alunos com dificuldades de aprendizagem, os problemas com a gestão da escola e o número de alunos na sala de aula, além da sensação de ausência de suporte ou acompanhamento pedagógico.

Devemos considerar, porém, que a pesquisa coletou a experiência de 87 professores que em sua maioria está baseada na região sudeste do país, faz-se necessário, então, pesquisas que envolvam mais profissionais de diferentes regiões para que esses dados sejam analisados e tenham-se uma mais real aferição de que há ou não um padrão prevalecente nos resultados.

\section{REFERÊNCIAS}

ALIC, M. Bilingualism/Bilingual education. Disponível em: < http://www.healthofchildren.com/B/Bilingualism-Bilingual-Education.html>. Acesso em: 29/04/2018.

ANDERSON, G. The 5 Challenges of CLIL - (05m14s) - Cambridge English Teacher. Disponível em: < https://www.youtube.com/watch?v=mm8216t4Uaw>. Acesso em: 12/05/2018.

BANEGAS, D. L. (2012). CLIL teacher development: Challenges and experiences. Latin American Journal of Content \& Language Integrated Learning, 2012. Disponível em: < https://www.unifg.it/sites/default/iles/allegatiparagrafo/20-012014/banegas_clil_teacher_development.pdf). Acesso em: 18/04/2018. 
CAMBRIDGE INTERNATIONAL EXAMINATIONS. Bilingual learners and bilingual education. Cambridge, $2015 . \quad$ Disponível em: $<$ http://www.cambridgeinternational.org/images/271190-bilingual-learners-andbilingual-education.pdf>. Acesso em: 08/05/2018.

COYLE D., HOOD P., MARSH D. (2010). Content and Language Integrated Learning. Cambridge: Cambridge University Press.

DALTON-PUFFER, C. (2011). Content-and-language integrated learning: From practice to principle? Annual Review of Applied Linguistics, 31(1), 182-204.

EU, ESTUDANTE. Estudo aponta quais são as principais reclamações dos professores. Disponível em: <http://www.correiobraziliense.com.br/app/noticia/euestudante/professor/2015/03/30/professor_interna,477560/estudo-aponta-quais-saoas-principais-reclamacoes-entre-professores.shtml>. Acesso em: 29/04/2018.

LAVROV, A. What made English the lingua franca? Disponível em: $<$ https://www.quora.com/What-made-English-the-lingua-francas. Acesso em: 29/04/2018.

LIMA, D. Como começou o ensino de inglês no Brasil? Disponível em: < https://www.inglesnapontadalingua.com.br/2017/03/como-comecou-o-ensino-deingles-no-brasil.html>. Acesso em: 29/04/2018.

MARSH, David on CLIL. 2010. (09m08s). Disponível em: $<$ https://www.youtube.com/watch?v=-Czdg8-6mJA>. Acesso em: 12/05/2018

MELLO, H. A. B., Educação bilíngue: uma breve discussão, 2010.

MINISTÉRIO DA EDUCAÇÃO. Educação Escolar Indígena: diversidade sociocultural indígena ressignifi cando a escola. Brasília, abril de 2007. Disponível em: http://portal.mec.gov.br/secad/arquivos/pdf/educacaoindigena.pdf. Acesso em: 20/04/2018. 
PENA DÍAZ, C. \& PORTO REQUEJO, M. (2008). Teacher beliefs in a CLIL education project. Porta Linguarum, 10, 151-161.

REVISTA EDUCAÇÃO. Dois idiomas, uma criança. Disponível em: <http://www.revistaeducacao.com.br/dois-idiomas-uma-crianca/>. Acesso em: 04/05/2018.

SANTOS, E. E. O Ensino Da Língua Inglesa No Brasil. BABEL: Revista Eletrônica de Línguas e Literaturas Estrangeiras n.01, dezembro de 2011.

SIMAS, A. Professores e os desafios dentro da sala de aula. Disponível em: <http://www.gazetadopovo.com.br/educacao/professores-e-os-desafios-dentro-dasala-de-aula-bsmeehc611tmnmdyxmr5jrjny>. Acesso em: 30/04/2018.

SOUSA, C. T. Os principais desafios da docência bilíngue no ensino regular privado no Brasil, 2018. Disponível em: < https://docs.google.com/forms/d/1MxV8K3JzRspghjPabrngZQYwOnZp0KXV3Q5Pdj XS3FY/edit\#responses>. Acesso em: 31/03/2019.

Enviado: Dezembro, 2019.

Aprovado: Setembro, 2020. 